\title{
Diel foraging and shelter use of large juvenile brown trout (Salmo trutta) under food satiation
}

\author{
J. Conallin ${ }^{(1,2)^{*}}$, M. Jyde ${ }^{(1)}$, K. Filrup ${ }^{(1)}$, and S. Pedersen ${ }^{(3)}$
}

Received August 27, 2011

Revised November 19, 2011

Accepted November 29, 2011

\section{ABSTRACT}

Key-words: The diel partitioning of juvenile brown trout Salmo trutta foraging behaviour diel habitat use, is controlled by a number of factors including predation risk, competition, foraging, food availability, juvenile brown trout, cover use temperature and food availability. The present study uses PIT-tagging and visual observation to asses the use of shelter and foraging behaviour of Danish wild juvenile brown trout $(13.5-15.6 \mathrm{~cm})$. The experiment was conducted in a fluvarium and the fish were fed to satiation. It was hypothesised that food satiation would promote nocturnal foraging and increase daytime shelter use. Our results showed a significant difference in diel shelter use between day and night with a significant increase in shelter use during daytime conditions. Visual observations showed a significant preference for nocturnal feeding. Together with the significantly reduced shelter use during the night, our results support the hypothesis that young stream living trout only feed during the day to the extent needed to sustain growth.

\section{RÉSUMÉ}

Comportement alimentaire journalier et utilisation d'abris par de grandes truites juvéniles (Salmo trutta), en condition de satiété alimentaire

\begin{abstract}
Mots-clés :
Le schéma nycthéméral du comportement alimentaire de juvéniles de truite fario utilisation nycthémérale de l'habitat, alimentation, disponibilité de la nourriture, truites juvéniles, Salmo trutta est contrôlé par un certain nombre de facteurs, dont le risque de prédation, la compétition, la température et la disponibilité alimentaire. La présente étude utilise des PIT-taggs et I'observation visuelle afin d'évaluer I'utilisation d'abris et le comportement alimentaire de truites fario juvéniles sauvages danoises (de 13,5 à 15,6 cm). L'expérience a été menée dans un fluvarium et les poissons ont été nourris à satiété. Il a été supposé que la satiété alimentaire favoriserait l'alimentation nocturne et augmentait l'utilisation des abris diurnes. Nos résultats ont utilisation d'abris montré une différence significative dans l'utilisation des refuges entre le jour et la nuit avec une augmentation significative de l'utilisation des refuges dans les conditions diurnes. Les observations visuelles ont montré une préférence marquée pour I'alimentation nocturne. Avec l'utilisation d'abris considérablement réduite pendant la nuit, nos résultats soutiennent l'hypothèse que les jeunes truites vivant en rivière se nourrissent pendant la journée, dans la mesure où cela est nécessaire pour soutenir leur croissance.
\end{abstract}

(1) Department of Environmental, Social and Spatial Change, Roskilde University, 4000 Roskilde, Denmark

(2) Murray Catchment Management Authority, 315 Victoria St., NSW, 2710 Deniliquin, Australia

(3) Technical University of Denmark - AQUA, National Institute of Aquatic Resources, Dept. of Inland Fisheries, 8600 Silkeborg, Denmark

*Corresponding author: john.conallin@cma.nsw.gov.au 


\section{INTRODUCTION}

The trade-off between feeding and avoiding predators affects foraging behaviour of juvenile brown trout (Salmo trutta L.) and Atlantic salmon (Salmo salar L.) together with water temperature, detection range and food abundance (Fraser and Metcalfe, 1997; Metcalfe et al., 1999; Orpwood et al., 2006). Juvenile trout and salmon have been found to change from being partly nocturnal in summer, dependant on food availability when water temperatures are above $10^{\circ} \mathrm{C}$, to being almost completely nocturnal in winter when temperatures drop below $10^{\circ} \mathrm{C}$ (Rimmer et al., 1983; Heggenes et al., 1993; Fraser and Metcalfe, 1997; Metcalfe et al., 1999). Fraser et al. (1993) found that the change from partly diurnal to almost completely nocturnal behaviour in small juvenile salmon $(88.2 \mathrm{~mm} \pm 0.73 \mathrm{~mm}$ ) was a gradual process that was independent of photo period and solely controlled by temperature.

Low temperatures reduce the reaction time of the fish (Johnson et al., 1996; Özbilgin and Wardle, 2002) making it less effective in avoiding endothermic predators such as piscivorous birds. The main daytime predator of juvenile brown trout in Denmark are grey herons (Ardea cinerea L.) which are numerous and often observed feeding in trout streams. Herons are especially important predators in shallow waters and during low water conditions (Geiger, 1983, 1984). The daytime nature of these major predators therefore facilitates night time activity especially in winter and under low water conditions, due to the reduced predation risk.

The drawback of nightime feeding is the reduced feeding efficiency due to low detection range of food items (Metcalfe et al., 1997). The feeding efficiency of salmonids is significantly reduced at light intensities lower than 0.1lx (Fraser and Metcalfe, 1997; Metcalfe et al., 1997). Despite the fact that drift increases at night (Allan, 1995) feeding efficiency with a clear sky and full moon still only be around $35 \%$ of efficiency in daylight, and will most likely only be around $10 \%$ (Metcalfe et al., 1997).

Low water temperatures minimize the digestion rates of the fish and reduce their energy requirements. The need for food is thus lowered during winter (Mortensen et al., 1988; Fraser et al., 1993; Metcalfe et al., 1999) and the trade-off between reduced energy requirements and increased risk of avian predation, especially at low water conditions, thus promotes nocturnal foraging during winter $\left(<10^{\circ} \mathrm{C}\right)$.

A shift in feeding behaviour towards nocturnal feeding has also been seen in small salmon parr $(77.1 \pm 3.8 \mathrm{~mm}$ ) under summer conditions if invertebrate drift is abundant (Orpwood et al., 2006), probably because the fish can acquire adequate amounts of food by feeding at night and yet maintain growth. Conversely, if drift is low, feeding will increase during the day despite an increase in avian predation-risk (Orpwood et al., 2006; Metcalfe et al., 1999). Nocturnal feeding thus facilitates survival at any time of year if food is abundant due to the reduced risk of avian predation. Food is seldom a limiting factor in Danish streams (Mortensen and Simonsen, 1983; Mortensen et al., 1988) and this could therefore facilitate nocturnal feeding among the juvenile brown trout in Danish Streams throughout the year.

Most experiments and surveys have been conducted on small 0+ and 1+ fish (50-100 mm), and mostly Atlantic salmon. Furthermore, Gries et al. (1997) found that larger salmon parr $(>110 \mathrm{~mm})$ were more nocturnally active than small salmon parr, indicating that there may be differences in foraging behaviour between these size classes (Fraser et al., 1995). Our study differs from previous studies by using larger $1+$ brown trout in the size range $13.6-15.6 \mathrm{~cm}$. We hypothesise that this size class are predominantly nocturnal feeders under growth temperature conditions found in Denmark when food is abundant, and thereby hypothesized to shelter more during the day than in the night. To test this we used a fluvarium with a constant temperature of $17.2^{\circ} \mathrm{C}$ where the trout were exposed to unrestricted feeding conditions and to light hours and levels mimicking light levels during the growth period.

\section{MATERIALS AND METHODS}

Shelter use in the fluvarium was recorded using Passive Integrated Transponder (PIT) tags in the test fish and fitting an antenna around their shelter. Fish were fed to satiation by a constant 
high rate of drifting defrosted chironomid larvae. Photo period, temperature and water velocity was held constant during the experiment. In addition, the fish were visually observed to determine circadian foraging activity pattern.

A total of 16 wild trout (mean length $144.5 \pm 8.5 \mathrm{~mm}$, mean weight $29.6 \pm 4.9 \mathrm{~g}( \pm$ S.D.) were used and the first round of observations was initiated after four days of recovery from tagging. Fish were fed during this time. Four fish were transferred at a time to individual sections; each section measuring $(L \times W \times D) 85.5 \pm 3.3 \times 51.3 \pm 2.3 \mathrm{~cm} 14.6 \pm 0.5 \mathrm{~cm}( \pm$ S.D. $)$ in a fluvarium, each section equipped with a shelter. The shelters were circular plastic tubes (diameter: $100 \mathrm{~mm}$, length: $200 \mathrm{~mm}$ ) fitted with an antenna around the middle of the tube. Shelters were covered with AstroTurf ${ }^{\circledR}$ to avoid the antenna from registering a fish on top or next to the shelter, so only fish inside the shelter were recorded. The fluvarium was glass-sided to allow visual observation of the fish. Temperature and water velocity in each section was held constant (mean temp. $17.2 \pm 1.5^{\circ} \mathrm{C}( \pm$ S.D. $)$, mean velocity $10.5 \pm 3.1 \mathrm{~cm} / \mathrm{s}( \pm$ S.D.) within the normal feeding range of brown trout (Elliot, 1981). Sections were separated by a coarse stainless steel mesh. Thawed chironomid larvae were supplied at a constant rate to the fluvarium from feed dispensers. Fish were allowed $24 \mathrm{~h}$ to acclimatize in their individual compartment before observations of behaviour were initiated. Data collection started at 2100 and was performed for $48 \mathrm{~h}$. The photo-period was kept constant ( $12 \mathrm{~h}$ light : $12 \mathrm{~h}$ dark) during both acclimatisation and observations in the experimental arena. Dawn, 0600-0700; dusk, 1700-1800. The daylight had a light intensity of $36.97 \pm 12.10$ lux $( \pm$ S.D.), dawn/dusk $0.64 \pm 0.25$ lux ( \pm S.D.) and night $0.088 \pm 0.036$ lux ( \pm S.D.), matching the light levels encountered in nature (Metcalfe et al., 1997; Fraser and Metcalfe, 1997).

Visual observations of each fish were performed over two $24 \mathrm{~h}$ periods during the $48 \mathrm{~h}$ of data collection. Each fish was observed on 10 occasions during the $24 \mathrm{~h}$ period. Four observations were collected at night, 4 during the day and one observation during dawn and dusk. Each round of observations had a duration of $15 \mathrm{~min}$ on each fish during which the behaviour was noted. Night time observations were made possible with dim red light (Petzl ${ }^{\circledR}$ TACTIKKA ${ }^{\circledR}$ PLUS headlamp set on the lowest light intensity) held at a distance of $50-75 \mathrm{~cm}$ from the tank. Behavioural categories were:

- hiding in shelter - the main part of the fish is inside the shelter;

- resting outside the shelter - immobile on the substrate, holding position outside the shelter or in one of the corners of the experimental arena;

- actively feeding - the fish is holding position above the substrate in open water or swimming actively around. Occasional outbursts towards food items may occur.

The data was grouped in the following categories: dawn (0600-0700), day (0700-1700), dusk (1700-1800) and night (1800-0600) and compared to a $\chi^{2}$-distribution by Friedman's test for paired data to analyse for variance between categories. The categories were subsequently comparied two by two by Wilcoxons test for paired samples.

\section{RESULTS}

\section{> PIT MONITORING}

The use of shelter varied between individual fish and averages of the fish used in the analysises are summarized in Figure 1. There was a significant difference in shelter use between the four time categories: dawn; $23.0 \pm 5.6 \%$, (mean \pm S.E.) day; $29.3 \pm 7.9 \%$, (mean \pm S.E.) dusk; $23.4 \pm$ $7.9 \%$, (mean \pm S.E.), and night $11.1 \pm 4.6 \%$ (mean \pm S.E.) (Friedman two-way analysis of variance; $P=0.026$ ). Median shelter use between night and day was signifcantly different (Wilcoxons test for paired samples; $P=0.023$ ) with the highest shelter use during the day. The use of shelter at dawn was also significantly higher than both the hour before dawn (Wilcoxons test for paired samples; $P<0.001$ ) and after (Wilcoxons test for paired samples; $P=0.046$ ). The lowest observed shelter use were the $4 \mathrm{~h}$ prior to dawn and two hours after dusk (Figure 1). 


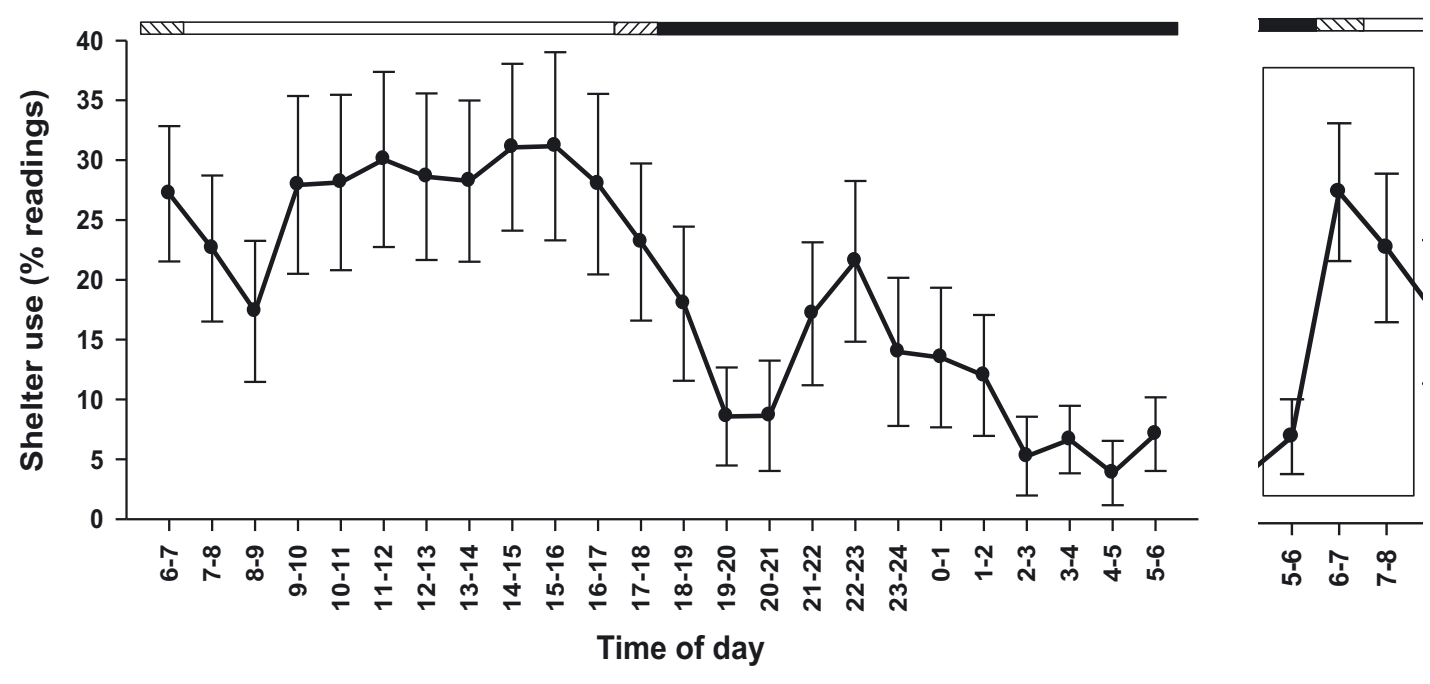

\section{Figure 1}

Summarized diel shelter use of juvenile smolt size brown trout. Mean ( \pm S.E.) percentage shelter use pr. hour are presented. Average over 2 days, for all fish. The white part of the horizontal bar at the top of the graph represents daylight, crossed sections represent dawn and dusk and the black parts represent night. Dawn $\pm 1 \mathrm{~h}$ is also marked with a box.

\section{> VISUAL OBSERVATIONS}

There were significant differences in the intesity of feeding, (Friedman Two-Way Analysis of Variance; $n=7 ; P<0.001$ ). The fish fed significantly more at night than during dawn (Wilcoxson's test for paired data; $n=7 ; P<0.01$ ), day (Wilconson's test for paired data; $n=7 ; P<0.01$ ) and dusk (Wilcoxson's test for paired data; $n=7 ; P<0.01$ ). The fish were foraging on average $41.4 \pm$ $13.4 \%$ (mean \pm S.E.) of the observed time at night, and the foraging rates at all other times were never higher than $7.6 \pm 4.2 \%$ (mean \pm S.E.) of the time. Fish observed away from the shelter were mostly resting in close proximity to shelter, and if disturbed darted straight back into the shelter.

\section{DISCUSSION}

Nocturnal foraging in juvenile trout and salmon has been suggested to improve the chance of survival in winter (Fraser et al., 1993; Heggenes et al., 1993; Fraser et al., 1995; Metcalfe et al., 1999), and studies suggest that juvenile salmon also feed predominately nocturnally in warmer conditions if food availability is adequate (Gries et al., 1997; Orpwood et al., 2006). The present study shows a significant preference for nocturnal activity at water temperatures within the growth range for juvenile brown trout in Danish streams during summer. In general, the time spent in shelter appeared low both during day and at night, using the PIT technology, but this could be explained by the trout's increased metabolism due to the temperature applied (Fraser et al., 1995) forcing them to feed frequently and thus leave their shelters. However, our visual observations contradicted this assumption by showing that they only fed rarely during the day, and spent most of their time resting in close proximity to the shelter. Visual observations showed that foraging was almost exclusively at night occurring about $40 \%$ of the time, whereas values for dawn, day and dusk were all less than $7 \%$. This was a clear indication that the fish were feeding to satiation nocturnally and were not forced to forage during the day to maintain metabolism and sustain growth, thereby reducing the trade-off between foraging and exposure to predators (Orpwood et al., 2006). At night when avian predators are not active, movement and foraging activity can be increased without elevating the risk of predation. 
It has been shown that just the awareness of a shelter being present increased fitness in juvenile salmon due to a lowered Standard Metabolic Rate (SMR) and fish aware of a shelter did not necessarily use the shelter, but if a predator appeared, the fish could dart into the shelter immediately (Millidine et al., 2006). This type of behaviour was seen on several occasions during the study, when disturbed by the changing of the feed dispensers, the fish would immediately dart into the shelter.

There was also a significant difference in use of shelter between dawn and night, and between the hour before dawn and the hour after dawn. This could be due to an inherent fear of avian predators which may start hunting as soon as the light levels start to rise. Feeding efficiency increases in this period but the same could be true for the predation risk and if net energy uptake compared to predation risk is too small, hiding increases the chance of survival. In addition grey heron are size selective predators preferring larger fish over smaller ones (Gwiazda and Amirowicz, 2006). Furthermore, Geiger (1984) found that the profitability of herons feeding on trout were size dependent with an optimum size range between $10-20 \mathrm{~cm}$. Therefore the larger juvenile size class used in this experiment would be more at risk of predation than the small parr or fry size classes in small Danish streams, and would thus have an increasing need for higher shelter use than smaller size classes during the day.

\section{CONCLUSION}

Our results show that there is a significant difference in diel shelter use of large juvenile Danish brown trout under experimental conditions, and that there was a significant increase in shelter use under daytime conditions. Combined with visual observations a significant preference for night time feeding was observed, indicating that large juvenile brown trout are primarily nocturnal feeders in Danish streams with adequate food supply. The hypothesis proposed by Orpwood et al. (2006), that fish only feed during the day to the extent needed to sustain growth, is thereby supported also in the case of juvenile Danish brown trout under experimental conditions. Our project also showed the importance of using visual observations of behaviour in combination with small scale technological studies.

\section{ACKNOWLEDGEMENTS}

The study was conducted in relation to the research project Climate change impacts on ecological conditions in streams, contact No. 247-06-0474. We would like to thank Jes Dolby, DTU Aqua for technical assistance, Ph.D. student Jon Christian Svendsen DTU Aqua for valuable criticism and Associate Professor Morten Foldager Pedersen, Department of Environmental, Spatial and Social change, Roskilde University for help with the statistics.

\section{REFERENCES}

Allan J.D., 1995. Stream Ecology, Structure and function of running waters, Chapman and Hall.

Fraser N.H.C., Heggenes J., Metcalfe N.B. and Thorpe J.E, 1995. Low summer temperatures cause juvenile Atlantic salmon to become nocturnal. Can. J. Zool., 73, 446-451.

Fraser N.H.C. and Metcalfe N.B., 1997. The costs of becoming nocturnal: feeding efficiency in relation to light intensity in juvenile Atlantic Salmon. Funct. Ecol., 11, 385-391.

Fraser N.H.C., Metcalfe N.B. and Thorpe J.E., 1993. Temperature-dependent switch between diurnal and nocturnal foraging in salmon. Proc. Roy. Soc. Lond. B, 252, 135-139.

Geiger C., 1983. Untersuchungen zum Graureiherproblem. Schriftenreihe Fischerei, Bundes amt für Umweltschutz, Bern., 41, 46-75.

Geiger C., 1984. Graureiher Ardea cinerea und Fischbestand in Fliessgewässern. Orn. Beob., 81, 111-131. 
Gries G., Whalen K.G., Juanes F. and Parrish D.L., 1997. Nocturnal activity of juvenile Atlantic salmon (Salmo salar) in late summer: evidence of diel activity partitioning. Can. J. Fish. Aquat. Sci., 54, 1408-1413.

Gwiazda G. and Amirowicz A., 2006. Selective foraging of grey heron (Ardea cinerea) in relation to density and composition of the littoral fish community in a submontane dam reservoir. Waterbirds, 29, 226-232.

Heggenes J., Krog O.M.W., Lindås O.R., Dokk J.G. and Bremnes T., 1993. Homeostatic behavioural responses in a changing environment: brown trout (Salmo trutta) become nocturnal during winter. J. Anim. Ecol., 62, 295-308.

Johnson T.P., Bennet A.F. and McLister J.D., 1996. Thermal dependence and acclimation of fast start locomotion and its physiological basis in rainbow trout (Oncorhynchus mykiss). Physiological Zoology, 69, 276-292.

Metcalfe N.B., Valdimarsson S.K. and Fraser N.H.C., 1997. Habitat profitability and choice in a sit-andwait predator: juvenile salmon prefer slower currents on darker nights. J. Anim. Ecol., 66, 866-875.

Metcalfe N.B., Fraser N.H.C. and Burns M.D., 1999. Food availability and the nocturnal vs. diurnal foraging trade-off in juvenile salmon. J. Anim. Ecol., 68, 371-381.

Millidine K.J., Armstrong J.D. and Metcalfe N.B., 2006. Presence of shelter reduces maintenance metabolism of juvenile salmon. Funct. Ecol., 20, 839-845.

Mortensen E., Geertz-Hansen P. and Marcus E., 1988. The significance of temperature and food as factors affecting the growth of brown trout, Salmo trutta L., in four Danish streams. Polskie Archiwum Hydrobiologii, 35, 533-544.

Mortensen E. and Simonsen J.L., 1983. Production estimates of the benthic invertebrate community in a small Danish stream. Hydrobiologia, 102, 155-162.

Orpwood J.E., Griffiths S.W. and Armstrong J.D., 2006. Effects of food availability on temporal activity patterns and growth of Atlantic salmon. J. Anim. Ecol., 75, 677-685.

Özbilgin H. and Wardle C.S., 2002. Effect of seasonal temperature changes on the escape behaviour of haddock, Melanogrammus aeglefinus, from the codend. Fish. Res., 58, 323-331.

Rimmer D.M., Paim U. and Saunders R.L., 1983. Autumnal habitat shift of juvenile Atlantic salmon (Slamo salar) in a small river. Can. J. Fish. Aquat. Sci., 40, 671-680. 